\title{
Gene Expression Profile of Renal Cell Carcinoma Clear Cell Type
}

\author{
Marcos F. Dall'Oglio, Rafael F. Coelho, Katia R. M. Leite, Juliana M. Sousa-Canavez, Paulo S. \\ L. Oliveira, Miguel Srougi
}

Division of Urology (MFDO, RFC, MS) and Laboratory of Medical Investigation (KRML), University of Sao Paulo Medical School, Sao Paulo, Brazil, Genoa Biotechnology (JMSC), Sao Paulo, Brazil, Laboratory of Genetics and Molecular Cardiology (PSLO), Heart Institute, University of Sao Paulo, SP, Brazil

\begin{abstract}
Purpose: The determination of prognosis in patients with renal cell carcinoma (RCC) is based, classically, on stage and histopathological aspects. The metastatic disease develops in one third of patients after surgery, even in localized tumors. There are few options for treating those patients, and even the new target designed drugs have shown low rates of success in controlling disease progression. Few studies used high throughput genomic analysis in renal cell carcinoma for determination of prognosis. This study is focused on the identification of gene expression signatures in tissues of low-risk, high-risk and metastatic RCC clear cell type (RCC-CCT).

Materials and Methods: We analyzed the expression of approximately 55,000 distinct transcripts using the Whole Genome microarray platform hybridized with RNA extracted from 19 patients submitted to surgery to treat RCC-CCT with different clinical outcomes. They were divided into three groups (1) low risk, characterized by pT1, Fuhrman grade 1 or 2, no microvascular invasion RCC; (2) high risk, pT2-3, Fuhrman grade 3 or 4 with, necrosis and microvascular invasion present and (3) metastatic RCC-CCT. Normal renal tissue was used as control.

Results: After comparison of differentially expressed genes among low-risk, high-risk and metastatic groups, we identified a group of common genes characterizing metastatic disease. Among them Interleukin-8 and Heat shock protein 70 were over-expressed in metastasis and validated by real-time polymerase chain reaction.

Conclusion: These findings can be used as a starting point to generate molecular markers of RCC-CCT as well as a target for the development of innovative therapies.
\end{abstract}

Key words: carcinoma, renal cell; microarray analysis; neoplasm metastasis; oncogenes; Interleukin 8, heat-shock protein; gene expression profiling

Int Braz J Urol. 2010; 36: 410-9

\section{INTRODUCTION}

Renal cell carcinoma (RCC) accounts for approximately $5 \%$ of all malignancies and is considered the most lethal urological cancer $(1,2)$. At early stages, it can be curable by surgical resection, but no effective treatment option is available for patients at advanced stage. Up to $30 \%$ of the cases have metastasis at initial diagnosis and $30 \%$ of initially organ-confined cases will develop metastases during follow-up $(3,4)$.

Treatment options available for patients with metastatic disease are very limited and currently tar- 
get therapy has been developed based on molecular peculiarities of RCC. Transcriptional profiling has also emerged as a powerful approach to identify the molecular mechanism underlying renal carcinogenesis and in predicting clinical outcomes (5). Gene expression profile may help to identify new biomarkers of aggressiveness and prognosis, selecting patients who could benefit from ancillary therapy. Microarray-based expression profiles have become a standard methodology in any high-throughput analysis.

There are few reported studies of gene expression in RCC clear cell type (RCC-CCT) which have assessed prognosis. Most of these studies used different subtypes of RCC, which is inappropriate since they have different carcinogenesis pathways and clinical behavior (6-9).

This study is focused on the identification of gene expression signatures in tissues of low-risk, high-risk and metastatic RCC-CCT. It was carried out using the Whole Genome Microarray platform, which simultaneously evaluates the mRNA level of 55.000 transcripts ESTs (Expressed Sequences Tags). The resulting expression panel is a statistical representation of physiological responses occurring in the finely tuned transcriptional regulation.

\section{MATERIALS AND METHODS}

\section{Patients and Tumor Samples}

Tissue samples of RCC-CCT obtained from the surgical specimens extracted from open nephrectomy of 19 patients were evaluated. The patients were divided in three groups: 1) Low risk RCC-CCT (Fuhrman nuclear grade 1 or 2, pT1 and no microvascular neoplastic invasion or tumor necrosis); 2) High risk RCC-CCT (Fuhrman nuclear grade 3 or 4 all staged pT3, all tumors had necrosis and microvascular neoplastic invasion), and 3) Metastatic RCC-CCT. Group 1 was composed of five men and two women submitted to tumor resection or partial nephrectomy; mean age 53.3 years-old (median 53, range 48-56), pT1, mean tumor size of $3.7 \mathrm{~cm}$ (median 3, range 1.86.5), Fuhrman grade 1 or 2 , no microvascular invasion or necrosis. Group 2 was constituted of four males and one female submitted to radical nephrectomy, mean age 60 years-old (median 65, range 39-73), T2-3 mean tumor size of $8.2 \mathrm{~cm}$ (median 9, range 3.9-11), Fuhrman grade 3 or 4 with necrosis and microvascular invasion present. Group 3 was characterized by seven patients with metastatic RCC, (six males and one female) mean age 57.7 years-old (median 60, range 39-69) extracted from metastatic specimens of the primary tumor. The control group was a pool of normal cortical renal tissue from 4 patients with chronic kidney infections.

Surgical specimens were immediately sent to surgical pathology laboratory, and frozen at $-170^{\circ} \mathrm{C}$ in liquid nitrogen maximum after 15 minutes. Institutional Review Board approved the protocol and informed consent was obtained from all patients.

\section{Microarray Experiment}

Frozen tissue samples were mechanically disrupted in liquid nitrogen and total RNA was extracted with Trizol reagent according to a preestablished protocol (Invitrogen Life Technologies, Carlsbad, CA). For each of the three group described above, $10 \mu \mathrm{g}$ of total RNA from each tissue sample was distributed between three pools. Double-stranded cDNAs were synthesized from $10 \mu \mathrm{g}$ of total RNA using SuperScript Choice double-stranded cDNA synthesis kit from Invitrogen following the manufacturer's protocol. cDNAs were purified by phenol/chloroform extraction and ethanol precipitation. Biotin-labeled cRNAs were synthesized by an in vitro transcription reaction using the BioArray HighYield RNA Transcript Labeling Kit (Enzo Diagnostics, Farmingdale, NY). cRNAs were purified from the in vitro transcription reaction using RNeasy Mini kit (Qiagen, Valencia, CA). Biotin-labeled cRNA was generated from each sample following the manufacturer's protocol. cRNA was hybridized onto CodeLink ${ }^{\circledR}$ whole genome microarray slides, washed and hybridized cRNA species were detected using Cy5-Streptavidin (Amersham, UK). Slides were scanned using GenePix Personal 4100A Microarray Scanner (Axon Instruments) and analyzed with CodeLink ${ }^{\circledR}$ Expression Analysis software. 


\section{Microarray Statistical Analysis}

Statistical analysis of the CodeLink ${ }^{\circledR}$ microarray slides was performed using the publicly available R statistical environment (http://www.r-project. org). The normalization and background correction were performed using the LIMMA package (Linear Models for Microarray Analysis) (10); a part of the Bioconductor Microarray Suite (www.bioconductor. org). The background noise was corrected using the normEXP algorithm and the values were normalized by a cyclic LOESS smooth function with a hundred of interactions using the a adjusting parameter of 1.0.

The normalized data were organized locally and using a Perl (http://www.perl.org) script we determined the minimum variation (fold change) threshold accepted as been significant. Datasets of each histological group were compared in a pairwise fashion. For each comparison performed, the fold change for a given spot was calculated. These values were distributed and the mean and standard deviation (SD) values of expression variation of all genes were determined. A gene was accepted as differently expressed if its expression variation was greater than the mean plus one SD or lower than the mean minus one SD. Finally, only genes accepted as significant on all comparisons were selected. This group of candidate genes were identified and organized locally. The gene lists were numerically sorted and the top UP and DOWN regulated genes were determined for each comparison. Functional classification of these genes was performed using Gene Ontology Consortium 2000.

\section{Quantitative Real-Time PCR and Gene Expression}

For qRT-PCR gene expression validation we evaluated 7 patients from group 1 (Low risk RCC-CCT), 5 patients from group 2 (High risk RCC-CCT) and 7 patients from group 3 (Metastatic RCC-CCT).

Total RNA extraction was performed using Trizol (Invitrogen Life Technologies, Carlsbad, CA) as mentioned previously. Pureness and concentration of RNA were measured in a spectrophotometer
(260/280 nM), and integrity was verified in an Agilent 2100 bioanalyzer (Agilent Technologies, Santa Clara, CA, USA). Synthesis of cDNA was performed from at least $5 \mu \mathrm{g}$ of total RNA with the enzyme M-MLV reverse transcriptase and random primers (Invitrogen Life Technologies, Carlsbad, CA, USA). The reactions were incubated at $65^{\circ} \mathrm{C}$ for $5 \mathrm{~min}$ followed by $37^{\circ} \mathrm{C}$ for $1 \mathrm{~h}$ and finally $95^{\circ} \mathrm{C}$ for $5 \mathrm{~min}$. The cDNA reactions were diluted to $100 \mu \mathrm{L}$ in nuclease-free water (Invitrogen Life Technologies, Carlsbad, CA, USA) and stored at $-20^{\circ} \mathrm{C}$ until further use.

The expression of two genes was analyzed from cDNA through the qRT-PCR technology in the Abi7500 platform using the TaqMan ${ }^{\circledR}$ protocol (Applied Biosystems). TaqMan ${ }^{\circledR}$ Endogenous Control Assay ID is Hs99999907-m1 (B2M) and Gene Expression Assay IDs are Hs00359147-s1 (HSPA1A and HSPA1B) and Hs00174103-m1 Interleukin 8 (IL-8). cDNA $(2 \mu \mathrm{L})$ from each tumor sample was added to a PCR reaction mix containing $1 \mathrm{X}$ TaqMan ${ }^{\circledR}$ Universal PCR Master Mix, AmpErase ${ }^{\circledR} \mathrm{UNG}$ and $1 \mu \mathrm{L}$ Endogenous Control Assay or Gene Expression Assay (Applied Biosystems) in a $20 \mu \mathrm{L}$ reaction volume. The cycling conditions were $50^{\circ} \mathrm{C}$ for $2 \mathrm{~min}, 95^{\circ} \mathrm{C}$ for 10 min and 40 cycles of $95^{\circ} \mathrm{C}$ for $15 \mathrm{sec}$ and $60^{\circ} \mathrm{C}$ for $1 \mathrm{~min}$. The $\Delta \Delta \mathrm{CT}$ method was used to calculate the relative expression of the two target genes and the fold change in gene expression in tumor relative to normal tissues determined by $2-\Delta \Delta \mathrm{CT}$ (11).

\section{RESULTS}

Several analyses were performed to identify the differentially expressed genes among the three groups of patients and controls. A significant proportion of differently expressed genes were identified in each comparison tested, the microarray plots are shown in Figure-1. As regards to low risk RCC-CCT (Figure-1A), there was little dispersion of the features referring to the differences in genetic expression, which tends to be distributed in a straight line, next to zero. Therefore, low-risk tumors showed insignificant alterations in their genetic expression when compared to normal tissues. High-risk and metastatic tumors (Figures 1B and C) have shown a significant increase in the proportion of differently expression 
A

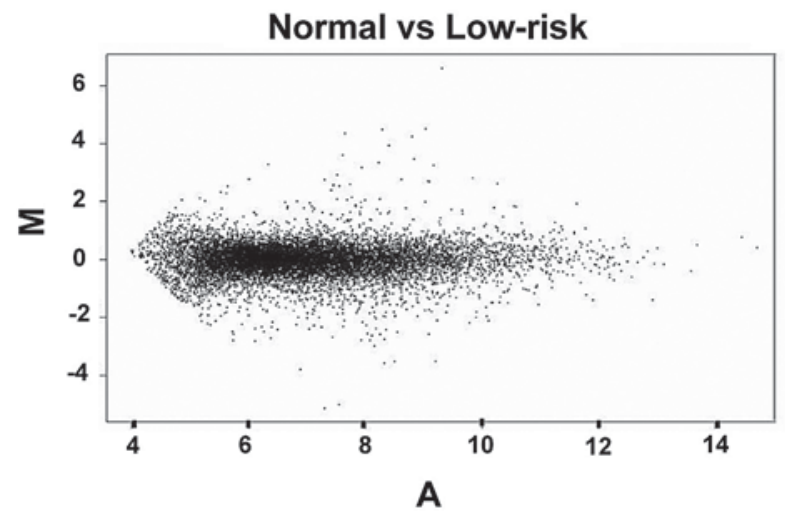

B

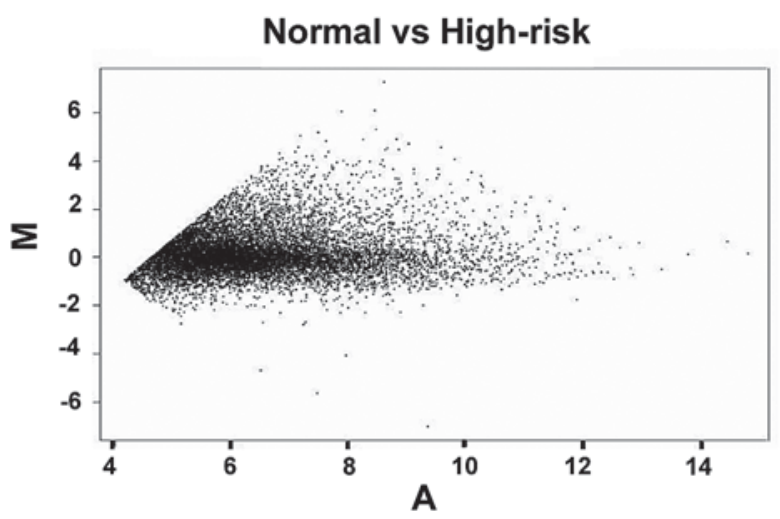

C

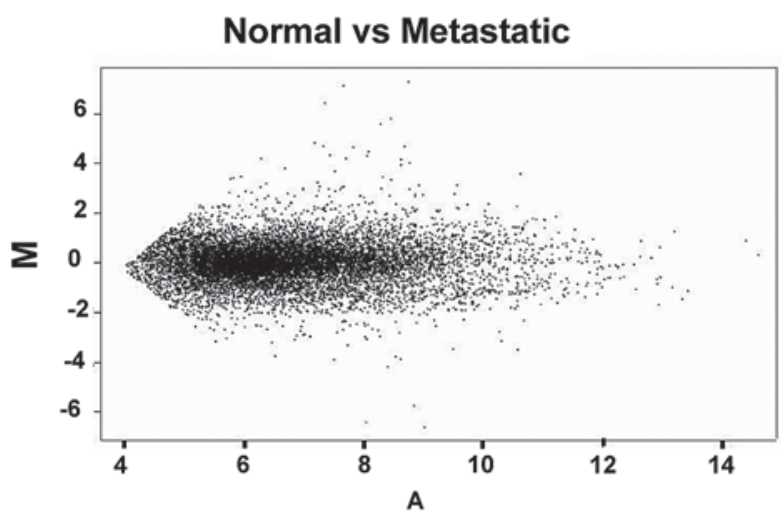

Figure 1 - Representation of gene expression variation in different ranges of intensity (MA-plot) between (A) normal vs. lowrisk, (B) normal vs. high-risk, and (C) normal vs. metastatic genes.

genes. This could reflect the expected disequilibrium in gene regulation of metastatic or prone to be tissues. The MA plots were used as quality control of the microarray experiments, since it is expected that variations in global gene expression tend to be subtle and any variation of linearity can reflect physiologi$\mathrm{cal} /$ pathological adaptations.

To identify the most important genes in the progression of RCC-CCT we selected the 50 most differentially expressed genes in each comparative group. After comparison among the differentially expressed genes in the low-risk, high-risk and metastatic groups, we identified a group of common genes, which presented either increase or reduction in their expression, from the low risk to the metastatic state. These genes are shown in Tables 1 and 2. When compared to the low-risk and high-risk groups, nine over-expressed and eleven under-expressed genes were found in the metastatic group. The differentially expressed genes in each comparison were functionally classified using the GO (Gene Ontology) database (Figure-2).

Two genes, IL-8 and HSP70, which had presented greater expression differences, were chosen to be validated by qRT-PCR. The validation was performed in the three groups mentioned as low-risk (LR), highrisk (HR) and metastatic (M) renal cell carcinomas. As seen in Figure-3, over expression of HSP70 and IL-8 was present in $100 \%(13 / 13)$ and $77 \%(10 / 13)$ respectively of metastatic carcinoma cases tested. The graph shows quantitative expression of genes in RCC tissue relative to normal cells. Fold change in gene expression was calculated using the $\Delta \Delta \mathrm{CT}$ method $(\mathrm{QRel}=$ $2-\Delta \Delta \mathrm{CT})$. Kruskal-Wallis test showed significant difference between metastatic and the other two groups $(p=0.0002)$. This pattern was significantly different from high-risk and low-risk carcinomas.

\section{COMMENTS}

Description of thousands of genomic sequences along with the technological development to identify the gene expression profile on a large scale has provided a remarkable improvement in the analysis of carcinogenesis process. This improved knowledge has had an impact on the latest advances regarding classification of neoplasias, identification of new diagnostic and prognostic markers, and finding of possible therapeutic targets. Until recently, the studies that evaluated genetic expression through the 
Gene Expression Profile of RCC Clear Cell Type

Table 1 - Genes with lower expression from Low-risk to metastatic stage.

\begin{tabular}{|c|c|c|}
\hline $\begin{array}{l}\text { Abbreviation } \\
\text { Official/GI* }\end{array}$ & $\begin{array}{l}\text { Identification } \\
\text { CodeLink }{ }^{\circledR}\end{array}$ & Gene Identification \\
\hline gi40578461 & 12878 & EST- atypical PKC isotype-specific interacting protein long variant mRNA \\
\hline C7 & 16412 & complement component 7 (C7) \\
\hline FCGBP & 16152 & Fc fragment of IgG binding protein \\
\hline PRAP1 & 46920 & proline-rich acidic protein 1 \\
\hline PCP4 & 19612 & Purkinje cell protein 4 (PCP4) \\
\hline gi52793583 & 24985 & EST-QV4-BN0090-210400-182-h09 BN0090 Homo sapiens cDNA \\
\hline gi3870266 & 38798 & $\begin{array}{l}\text { EST-qz33c05x1 NCI_CGAP_Kid11 cDNA clone IMAGE:2028680 3' similar to } \\
\text { gb:X02747 FRUCTOSE-BISPHOSPHATE ALDOLASE B }\end{array}$ \\
\hline WFDCD2 & 20765 & WAP four-disulfide core domain 2 transcript variant 1 \\
\hline gi1401452 & 23196 & $\begin{array}{l}\text { EST-zh66h10s1 Soares_fetal_liver_spleen_1NFLS_S1 cDNA clone IM- } \\
\text { AGE:4170913, }\end{array}$ \\
\hline
\end{tabular}

${ }^{*}$ GI = genomic identification according to National Institutes of Health data bank. (http://www.ncbi.nlm.nih.gov)

microarray technique in RCC had focused particularly on the description of genes for diagnostic molecular classification (6). The purpose of our research was the identification of gene expression profiles related to known anatomopathological parameters that are correlated to the prognosis (12). These genetic expression profiles can help to describe a comprehensible pattern via $R C C$ progression and metastatization. Among the genes identified in our study the most important ones are IL-8, and the heat shock protein (HSP-70) genes, which are closely linked to the known carcinogenesis way of the clear cell carcinoma.

Table 2 - Genes with higher expression from low-risk to metastatic stage.

\begin{tabular}{|c|c|c|}
\hline $\begin{array}{l}\text { Abbreviation } \\
\text { Official/GI* }\end{array}$ & $\begin{array}{l}\text { Identification } \\
\text { CodeLink }{ }^{\circledR}\end{array}$ & Gene Identification \\
\hline gi22685430 & 34169 & AGENCOURT_7932449 NIH_MGC_72 cDNA clone IMAGE:6156942 5' \\
\hline R39367 & 11050 & clone 24734 mRNA sequence \\
\hline DUSP2 & 16648 & dual specificity phosphatase 2 \\
\hline HSPA1A & 39816 & heat shock $70 \mathrm{kDa}$ protein $1 \mathrm{~A}$ \\
\hline HSPA1B & 50162 & heat shock $70 \mathrm{kDa}$ protein $1 \mathrm{~B}$ \\
\hline gi66255625 & 49424 & EST-hypothetical protein LOC90637 \\
\hline IL8 & 24261 & interleukin 8 \\
\hline- & 36561 & EST-mRNA; cDNA DKFZp667A182 (from clone DKFZp667A182) \\
\hline UBC & 6469 & ubiquitin $\mathrm{C}$ \\
\hline gi5863270 & 45082 & $\begin{array}{l}\text { EST-UI-H-BI0-aai-f-11-0-UIs1 NCI_CGAP_Sub1 cDNA clone IM- } \\
\text { AGE:2709644 3, }\end{array}$ \\
\hline gi2077388 & 29444 & $\begin{array}{c}\text { EST-zu07b03.r1 Soares_testis_NHT cDNA clone IMAGE:731117 5' similar to } \\
\text { contains MER30.t2 MER30 repetitive element }\end{array}$ \\
\hline
\end{tabular}

${ }^{*}$ GI = genomic identification according to National Institutes of Health data bank. (http://www.ncbi.nlm.nih.gov) 


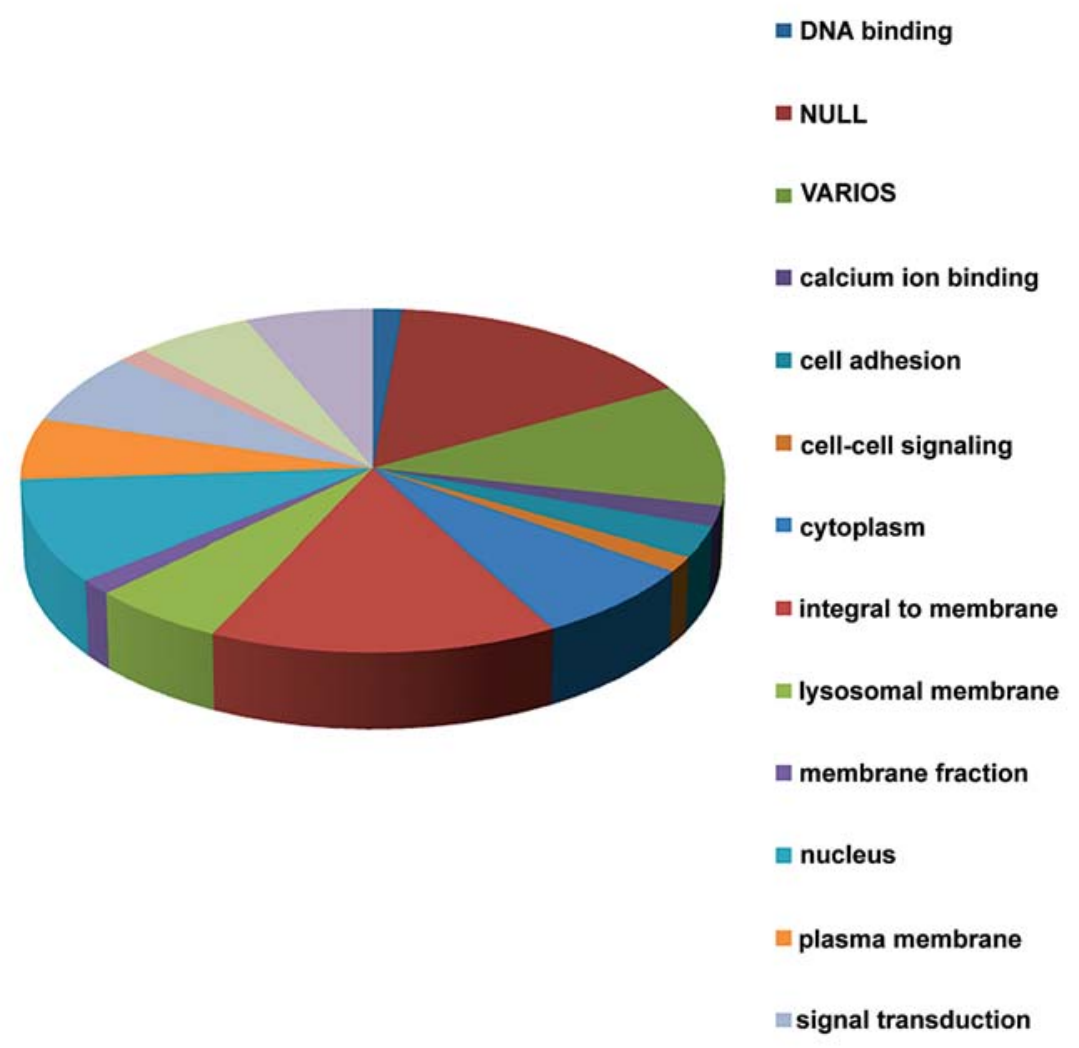

Figure 2 - Functional classes of overexpressed genes when comparing high-risk tumors to low-risk tumors.

The gene profiles of the high-risk and metastatic disease are quite similar, and this was described by Jones et al. (7) These authors, studying clear cell type RCC, identified a similar profile of genetic expression among both locally advanced and metastatic tumors, which was named metastatic signature. Kosari et al. (9) in a study quite similar to ours, also identified genes expressed in both aggressive and metastatic carcinomas.

In recent years, the analysis of the gene expression profile on a large scale has been widely used to define genetic expression patterns that can be related to neoplasia aggressiveness (13). Current studies on RCC have sought the identification of new prognostic markers. By studying 16 RCCs in a platform comprising 21,632 genes, (6) a correlation between the histological and genetic classifications in 14 renal tumors. Jones et al. was identified. (7), studying 65 RCC (23 CCC, 13 papillary, 7 chromophobes, 12 oncocytomas) and 24 normal renal tissues defined a genetic profile associated with the development of metastasis, based on a platform of 22,283 genes (Affymetrix). Liou et al. (8) studied six RCCs and compared the differentiated genic expression with six normal renal tissues. By using a platform of 7,129 genes (Affymetrics), they were able to demonstrate that $25 \%$ of genes are differentially expressed and among them, an over expression of adhesion molecules (laminin A and fibronectin) which would act in the progression of the neoplasia.

The membrane receptors, like the epidermal growth factor receptor (EGFR), were poorly expressed in the initial RCC, as pTla tumors; however, its overexpression was correlated with an increase in the tumor stage. These transmembrane glycoproteins interact with tyrosine kinase and promote invasion, metastasis and expression of biomarkers (14). Many target drugs have been studied in the attempt to inhibit cellular events acting directly on these receptors. Presently, tyrosine kinase inhibitory drugs have shown 


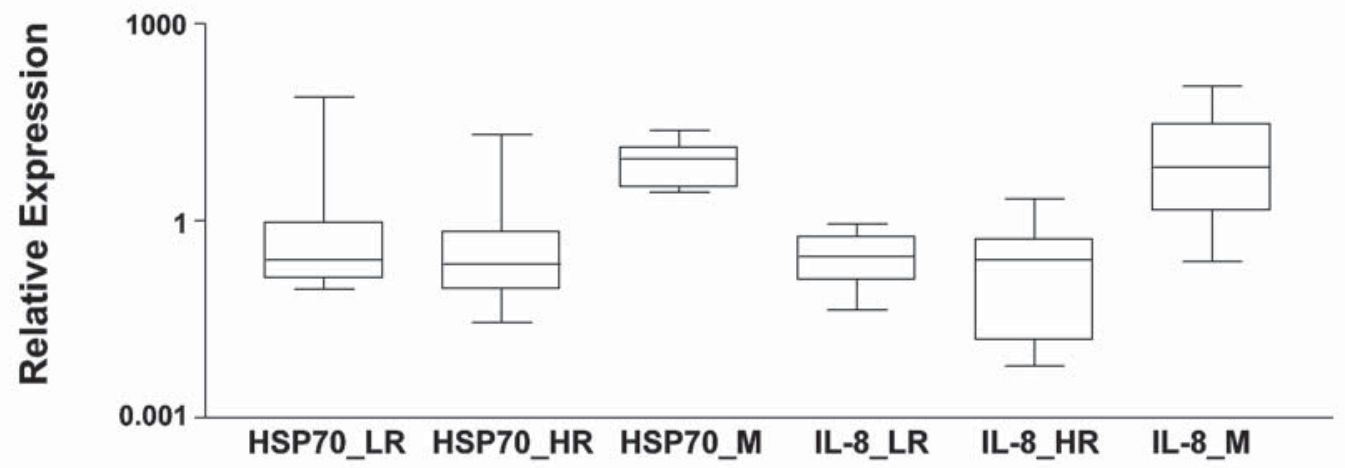

Figure 3 - Box-and-whisker plots of HSP70 and IL-8 expression in low-risk (LR), high-risk (HR) and metastatic (M) renal cell carcinoma.

promising results in cases of metastatic RCC, thus pointing to more reasonable expectations of disease control than isolated immunotherapy (15).

The VHL gene is responsible for the codification of a protein, which is part of the elongin $\mathrm{B}$ and $\mathrm{C}$ complex, whose function is the degradation of the hypoxia-induced factor (HIF-1). This factor is an upregulator of the tyrosine kinase VEGFR receptor, that is overexpressed in RCCs. VEGFR regulates the hypervascular characteristic of RCC $(16,17)$, which has already been the target for the development of inhibitory molecules and antibodies for therapeutic use. Both familiar and sporadic RCCs are related to mutation and/or loss of VHL gene, resulting in nonformation of the elongin B and C complex and HIF-1 accumulation. HIF-1 induces translation of genes related to angiogenesis, favoring the carcinogenesis. The VHL suppressor gene mutations are responsible for the VHL syndrome. The mutated gene is found in $75 \%$ of sporadic RCC cases (18). It is believed that the tumor necrosis factor alpha (TNF- $\alpha$ ) contributes to the VHL gene suppressive function (19); in our study, this gene was overexpressed in the low-risk cases in relation to the normal ones, validating Caldwell's theory.

Clear renal cell carcinoma occurs in approximately $80 \%$ of RCC cases, and a great deal of research shows different gene groups - either underexpressed or overexpressed - without significant intersections among the various studies. These discrepancies probably occur due to different criteria in the selection of the altered genes and the use of different microarray platforms with distinct anchored markers. Another aspect of criticism in any microarray analysis is the improper collection of neoplastic tissue and loss of cellular lineage in tumors, which are mostly heterogeneous (14).

Using qRT-PCR we were able to validate the overexpression of IL-8 and HSP-70 in metastatic RCC-CCT. HSP is expressed by cells under pathological and physiological conditions; its most important functions include homeostasis, apoptosis, and also a relevant role in antigenicity mediated by T cells (20). HSP 27 and 72 overexpression are clinically relevant (21), particularly HSP27 overexpression in CCR when compared to normal renal cells (22). Conversely, in our study HSP70 1A and 1B were overexpressed in metastatic cases in relation to low-risk and high-risk cases. The HSP 70 is considered one of the most powerful stimulants to human immune response and the structure and function of these proteins and their relation with immunity have been extensively investigated (23). HSP is an integral component of HIF and this interaction induces HSP overexpression. Drug-oriented actions inhibiting the HIF-HSP complex might exert an inhibitory potential over this important carcinogenesis mechanism; it is necessary, however, to distinguish the effects of the HSP family members (23).

IL-8 is over expressed by tumors and has been related to angiogenesis, mitotic activity and metastatization (24). Yoshida et al. (25) showed IL-8 expression in breast, ovary, pancreas and prostate carcinoma related to higher stage and tumor progression. 
It regulates metalloproteinases 2 and 9 promoting stromal infiltration and angiogenesis facilitating the metastatic progression.

Based on carefully analyzed molecular events in RCC, the benefits of individualized therapies will become prominent in the near future. However, considering that genetic alterations in cancer progression are complex and frequently imply multiple paths, the combination of new target-drugs for particular genes involved in each RCC histological subtype will be necessary.

\section{CONCLUSIONS}

Distinct gene expression profiles of low-risk, high-risk and metastatic RCCs were demonstrated, with emphasis on the progressive higher expression of the HSP 70 and IL-8 genes from Low-risk to metastatic stage. Based on our findings, it is possible to suggest these genes as starting points for prognostic molecular markers and/or targets for specific therapies.

\section{CONFLICT OF INTEREST}

None declared.

\section{REFERENCES}

1. Parkin DM, Bray F, Ferlay J, Pisani P: Global cancer statistics, 2002. CA Cancer J Clin. 2005; 55: 74-108.

2. Jemal A, Siegel R, Ward E, Hao Y, Xu J, Thun MJ: Cancer statistics, 2009. CA Cancer J Clin. 2009; 59: 225-49.

3. Uchida K, Miyao N, Masumori N, Takahashi A, Oda $\mathrm{T}$, Yanase M, et al.: Recurrence of renal cell carcinoma more than 5 years after nephrectomy. Int J Urol. 2002; 9: 19-23.

4. Levy DA, Slaton JW, Swanson DA, Dinney CP: Stage specific guidelines for surveillance after radical nephrectomy for local renal cell carcinoma. J Urol. 1998; 159: 1163-7.

5. van de Vijver MJ, He YD, van't Veer LJ, Dai H, Hart AA, Voskuil DW, et al.: A gene-expression signature as a predictor of survival in breast cancer. N Engl J Med. 2002; 347: 1999-2009.
6. Yang XJ, Sugimura J, Schafernak KT, Tretiakova MS, Han M, Vogelzang NJ, et al.: Classification of renal neoplasms based on molecular signatures. J Urol. 2006; 175: 2302-6.

7. Jones J, Otu H, Spentzos D, Kolia S, Inan M, Beecken WD, et al.: Gene signatures of progression and metastasis in renal cell cancer. Clin Cancer Res. 2005; 11: 5730-9.

8. Liou LS, Shi T, Duan ZH, Sadhukhan P, Der SD, Novick AA, et al.: Microarray gene expression profiling and analysis in renal cell carcinoma. BMC Urol. 2004; 4: 9.

9. Kosari F, Parker AS, Kube DM, Lohse CM, Leibovich BC, Blute ML, et al.: Clear cell renal cell carcinoma: gene expression analyses identify a potential signature for tumor aggressiveness. Clin Cancer Res. 2005; 11 : 5128-39.

10. Smyth GK: Limma: linear models for microarray data. In: Gentleman R, Carey V, Dudoit S, Irizarry R, Huber W, (ed.), Bioinformatics and computational biology solutions using R and bioconductor. New York, Springer. 2005; pp. 397-420.

11. Livak KJ, Schmittgen TD: Analysis of relative gene expression data using real-time quantitative PCR and the 2(-Delta Delta C(T)) Method. Methods. 2001; 25: 402-8.

12. Dall'Oglio MF, Arap MA, Antunes AA, Cury J, Leite KR, Srougi M: Impact of clinicopathological parameters in patients treated for renal cell carcinoma. J Urol. 2007; 177: 1687-91.

13. Yin-Goen Q, Dale J, Yang WL, Phan J, Moffitt R, Petros JA, et al.: Advances in molecular classification of renal neoplasms. Histol Histopathol. 2006; 21: 325-39.

14. Langner $\mathrm{C}$, Ratschek M, Rehak P, Tsybrovskyy O, Zigeuner R: The pT1a and $\mathrm{pT} 1 \mathrm{~b}$ category subdivision in renal cell carcinoma: is it reflected by differences in tumour biology? BJU Int. 2005; 95: 310-4.

15. Motzer RJ, Hutson TE, Tomczak P, Michaelson MD, Bukowski RM, Rixe O, et al.: Sunitinib versus interferon alfa in metastatic renal-cell carcinoma. N Engl J Med. 2007; 356: 115-24.

16. Hirota E, Yan L, Tsunoda T, Ashida S, Fujime M, Shuin $\mathrm{T}$, et al.: Genome-wide gene expression profiles of clear cell renal cell carcinoma: identification of molecular targets for treatment of renal cell carcinoma. Int J Oncol. 2006; 29: 799-827.

17. Staehler M, Rohrmann K, Haseke N, Stief CG, Siebels M: Targeted agents for the treatment of advanced renal cell carcinoma. Curr Drug Targets. 2005; 6: 835-46.

18. Foster K, Prowse A, van den Berg A, Fleming S, Hulsbeek MM, Crossey PA, et al.: Somatic mutations 
of the von Hippel-Lindau disease tumour suppressor gene in non-familial clear cell renal carcinoma. Hum Mol Genet. 1994; 3: 2169-73.

19. Caldwell MC, Hough C, Fürer S, Linehan WM, Morin PJ, Gorospe M: Serial analysis of gene expression in renal carcinoma cells reveals VHL-dependent sensitivity to TNFalpha cytotoxicity. Oncogene. 2002; 21 : 929-36.

20. Seliger B, Lichtenfels R, Kellner R: Detection of renal cell carcinoma-associated markers via proteome- and other 'ome'-based analyses. Brief Funct Genomic Proteomic. 2003; 2: 194-212.

21. Santarosa M, Favaro D, Quaia M, Galligioni E: Expression of heat shock protein 72 in renal cell carcinoma: possible role and prognostic implications in cancer patients. Eur J Cancer. 1997; 33: 873-7.
22. Lichtenfels R, Kellner R, Bukur J, Beck J, Brenner W, Ackermann A, et al.: Heat shock protein expression and anti-heat shock protein reactivity in renal cell carcinoma. Proteomics. 2002; 2: 561-70.

23. Javid B, MacAry PA, Lehner PJ: Structure and function: heat shock proteins and adaptive immunity. J Immunol. 2007; 179: 2035-40.

24. Koch AE, Polverini PJ, Kunkel SL, Harlow LA, DiPietro LA, Elner VM, et al.: Interleukin-8 as a macrophage-derived mediator of angiogenesis. Science. 1992; 258: 1798-801.

25. Yoshida T, Matsumoto E, Hanamura N, Kalembeyi I, Katsuta K, Ishihara A, et al.: Co-expression of tenascin and fibronectin in epithelial and stromal cells of benign lesions and ductal carcinomas in the human breast. J Pathol. 1997; 182: 421-8.

Accepted after revision: January 6, 2010

\section{Correspondence address:}

Dr. Marcos F. Dall'Oglio

Rua Barata Ribeiro, 398 - $5^{\circ}$ Andar

São Paulo, SP, 01308-000, Brazil

Fax: + $55113159-3618$

E-mail: marcosdallogliouro@terra.com.br

\section{EDITORIAL COMMENT}

In this nicely written paper by Dall'Oglio et al., the gene expression profile of clear cell type renal cell carcinoma (RCC) was conducted to identify the functional genes selectively expressed in low-, high-, and metastatic RCC patients. Although several groups have conducted tissue microarray studies focusing on RCC (1-4), the present study has several merits; firstly, the authors have evaluated the gene expression profiles of a uniform patient cohort (i.e. those with clear cell histology) removing study population heterogeneity as a confounding variable, secondly, the authors have stratified their study population according to risk of progression whereby allowing to better define the gene expression profiles of these prognostic subsets. It is clear to me that although major strides have been made in the systemic therapy of metastatic RCC (i.e. tyrosine kinase inhibitors, mTOR inhibitors), it remains clinically disappointing that a partial response or disease stability for a typical period of several months is noted in responders to these systemic agents. The treatment panacea for metastatic RCC (i.e. complete response rendering patients disease-free) will only likely come with a better understanding of the genetic and mechanistic pathways underlying this heterogeneous malignancy. Studies such as this will likely lead to a more personalized therapeutic approach to patients in which the genetic alterations specific to the various subtypes of RCC will be targeted. It is likely that in the not too distant future, a patient with 
metastatic RCC will undergo a pre-treatment percutaneous renal biopsy enabling us to not only identify the histologic tumor type but rather develop a tissue microarray identifying the specific genetic alterations in an individual patient's tumor which can then be targeted using a selective treatment combination and enabling a more personalized and highly effective therapeutic approach to be initiated.

\section{REFERENCES}

1. Dahinden C, Ingold B, Wild P, Boysen G, Luu VD, Montani M, et al.: Mining tissue microarray data to uncover combinations of biomarker expression pat- terns that improve intermediate staging and grading of clear cell renal cell cancer. Clin Cancer Res. 2010; 16: 88-98.

2. Rogers CG, Ditlev JA, Tan MH, Sugimura J, Qian $\mathrm{CN}$, Cooper J, et al.: Microarray gene expression profiling using core biopsies of renal neoplasia. Am J Transl Res. 2009; 1: 55-61.

3. Huang Y, Dai Y, Yang J, Chen T, Yin Y, Tang M, et al.: Microarray analysis of microRNA expression in renal clear cell carcinoma. Eur J Surg Oncol. 2009; 35: 1119-23.

4. Lane BR, Li J, Zhou M, Babineau D, Faber P, Novick $\mathrm{AC}$, et al.: Differential expression in clear cell renal cell carcinoma identified by gene expression profiling. J Urol. 2009; 181: 849-60.

Dr. Philippe E. Spiess

Department of Urologic Oncology H. Lee Moffitt Cancer Center Tampa, Florida, USA E-mail:philippe.spiess@moffitt.org 